\title{
Vibration white finger: a follow up study
}

\author{
LENA EKENVALL, A CARLSSON \\ From the Clinic of Occupational Medicine, Södersjukhuset, Stockholm, Sweden
}

ABSTRACT To study the course of vibration white finger (VWF) 55 men were re-examined three and a half to six years after the first examination. The patients were interviewed and finger systolio pressure after general body and local finger cooling was measured. The test results at the tw\& examinations were compared. At the follow up examination some patients experienced a subjective improvement of VWF symptoms but not until more than three years had passed after they hat stopped working with vibrating tools. To study the effect of diminished cold exposure on subjective symptoms, vibration exposed outdoor workers who changed to unexposed indoor work were studo ied separately. In this subgroup also improvement was reported only when more than three yearo had passed after the change of work, indicating that diminished cold exposure is not the primary explanation for the improvement. The cold provocation test, however, showed no tendency toward a diminished reaction of the vessels to cooling. Patients who continue to work with vibrating tools report a subjective increase in symptoms. This subjective impairment was reflected in an increase $\bar{B}$ reaction to cold as measured in the cold provocation test.

Recent studies have shown that patients with vibration white finger (VWF) subjectively improve after they have stopped working with vibrating tools. ${ }^{1-3}$ The course of VWF has mainly been studied in lumberjacks. In this occupation anti-vibration motor saws were introduced in the beginning of the 1970s. In addition to the diminished exposure to vibration the method of transport changed from motorcycles to cars during the study period. Thus there has been some discussion as to whether the improvement is due to decreased exposure to cold rather than to diminished exposure to vibrations. ${ }^{45}$

The patients' description of the symptoms has been the only way to study the course of VWF, since no objective tests exist that show improvement or impairment of the disease. ${ }^{6}$

The aim of the present study was to relate a possible change of VWF symptoms to continued/ discontinued vibration and cold exposure and to discover if any subjective change of the symptoms was reflected in the results of a cold provocation test.

\section{Subjects and methods}

All patients with a typical history of VWF who were examined between October 1979 and April 1982 com-

Accepted 27 August 1986 prised the study group. During this period the Taylon Pelmear symptom scale was consistently used to describe the cold induced symptoms, ${ }^{7}$ and measure ment of finger systolic pressure after general body ane local finger cooling was performed to evaluate the case history. 89 The occupations and smoking habif were always noted in the case histories.

Of the 68 patients initially included in the stud group, 10 had changed place of residence, two refused to participate, and one was dead. The remaining 5 (mean age 45.5 , SD 9.9 years) were reexamined between October and December 1985, three and half to six years (mean 4.3 , SD 0.8 years) after the primary examination. The study group is described and the test results at the first examination are showit in table 1.

The reexamination included an interview by physician with no prior knowledge of the patients. A questionnaire was used, including details about pos ible change of occupation, indoor or outdoor work, and nicotine habits. Symptom questions were formर lated to make it possible to grade the disease accorde ing to the Taylor-Pelmear symptom scale, but the patients were also directly asked if the VWF sympt toms were subjectively improved, stationary, of impaired. The cold provocation test was repeated. $\frac{\circ}{\mathbb{Q}}$

For the statistical analysis Wilcoxon's matched pairs signed ranks test ( 2 sided $p$ values) was use 
Vibration white finger: a follow up study

Table 1 Study group at the first examination. Data were collected from case histories. Medians and quartiles are shown. FSP $\%=$ Finger systolic blood pressure at $15^{\circ} \mathrm{C}$ and $10^{\circ} \mathrm{C}$ in per cent of the pressure in the finger at $30^{\circ} \mathrm{C}$, corrected for change in systemic pressure. ${ }^{8} \mathrm{~A}$ low value indicates a pronounced reaction of finger arteries on cooling

\begin{tabular}{|c|c|c|c|}
\hline Taylor stage & $l(n=14)$ & $\begin{array}{l}2 \\
(n=25)\end{array}$ & $\begin{array}{l}3-4 \\
(n=16)\end{array}$ \\
\hline $\begin{array}{l}\text { Age (years) } \\
\text { Outdoor work (\%) } \\
\text { Nicotine users (\%) } \\
\text { FSP\% } 15^{\circ} \mathrm{C} \\
\text { FSP\% } 10^{\circ} \mathrm{C}\end{array}$ & $\begin{array}{l}40(34-49) \\
86 \\
57 \\
43(0-72) \\
58(0-71)\end{array}$ & $\begin{array}{l}45(38-53) \\
48 \\
64 \\
46(0-79) \\
14(0-55)\end{array}$ & $\begin{array}{l}49(41-59) \\
63 \\
50 \\
40(0-78) \\
24(0-57)\end{array}$ \\
\hline
\end{tabular}

Table 2 Subjective change in the disease in patients subdivided according to number of years after change to unexposed work

\begin{tabular}{llll}
\hline & \multicolumn{3}{l}{ Unexposed work (years) } \\
\cline { 2 - 4 } & $\begin{array}{l}<0.5 \\
(n=18)\end{array}$ & $\begin{array}{l}0 \cdot 5-3 \\
(n=17)\end{array}$ & $\begin{array}{c}>3 \\
(n=20)\end{array}$ \\
\hline Improved & 1 & 1 & 8 \\
Stationary & 10 & 10 & 10 \\
Impaired & 7 & 6 & 2 \\
\hline
\end{tabular}

when comparing test results at the first and second examination; Fisher's exact test was used for $2 \times 2$ tables.

\section{Results}

The work status and the subjective change in VWF symptoms in the patient group at the second examination are shown in the figure. Ten patients reported a subjective improvement in VWF symptoms (table 2). Only one patient experienced no attacks and
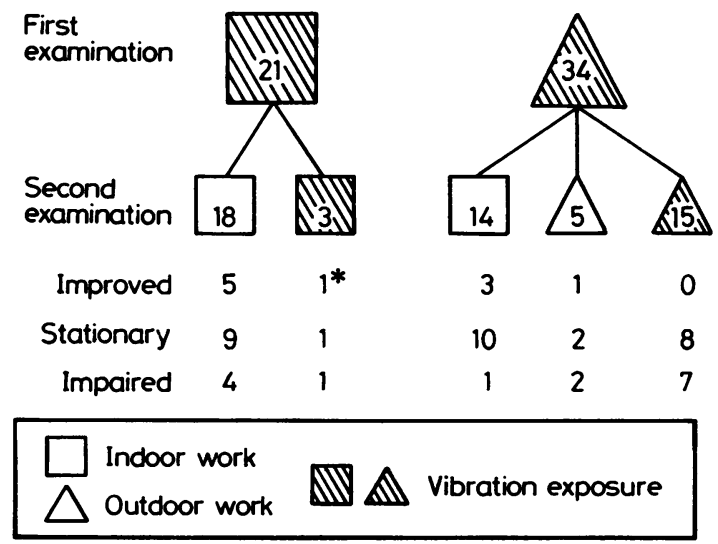

Change in work and subjective symptoms during follow up period. Only one improved patient was still exposed (*). He had cut his vibration exposure from two hours a day to two hours a week. another had improved to such an extent that a lower Taylor stage was found. More patients had improved in the group with an interval longer than three years from last exposure to vibration than those with a shorter exposure free interval $(p<0.025)$. Three of the 14 patients who had changed from exposed outdoor to unexposed indoor work (fig) reported an improvement in symptoms. All three had changed work more than three years before the reexamination. Five of 18 patients who had changed from exposed to unexposed indoor work were improved. Four of these had changed work more than three years before the reexamination. Thus outdoor workers, as the indoor workers, reported no improvement until more than three years had passed after exposure ended.

Fifteen patients reported a subjective impairment in symptoms (fig, table 2). Only two had changed to unexposed work more than three years before the reexamination. Five had deteriorated to such an extent that a higher Taylor grade was found.

Any effects of nicotine on symptom change could not be evaluated. Only five patients had stopped smoking during the follow up period; one reported improvement and one impairment. Five of the 10 patients with subjective improvement and 10 of the 15 impaired were initially smokers. This difference is not statistically significant.

In 43 patients complete cold provocation tests were performed at both examinations. On a group basis, the test results on cooling to $15^{\circ} \mathrm{C}$ and $10^{\circ} \mathrm{C}$ were unchanged between the two examinations. When the patient group was subdivided according to subjective change in the disease (table 3), only those considering themselves as impaired had a more pronounced reaction on cooling to $15^{\circ} \mathrm{C}(\mathrm{p}<0.05)$ and to $10^{\circ} \mathrm{C}$ $(p<0.01)$ at the second compared with the first examination. There was no significant change in the test results between the two examinations in the patients reporting a subjective improvement or stationary symptoms. The only patient who considered himself cured had closure of his digital arteries on cooling to $15^{\circ} \mathrm{C}$ and $10^{\circ} \mathrm{C}$; no systolic pressure could be registered in the finger. In none of the

Table 3 Test results in the patients subdivided according to subjective change in the disease. Only patients with complete cold provocation tests at both examinations are included in the table. Medians and quartiles are shown

\begin{tabular}{|c|c|c|c|}
\hline Subjectively & $\begin{array}{l}\text { Improved } \\
(n=6)\end{array}$ & $\begin{array}{l}\text { Stationary } \\
(n=26)\end{array}$ & $\begin{array}{l}\text { Impaired } \\
(n=I I)\end{array}$ \\
\hline $\begin{array}{c}\text { First examination: } \\
\text { FSP\% } 15^{\circ} \mathrm{C} \\
10^{\circ} \mathrm{C}\end{array}$ & $\begin{array}{l}45(0-74) \\
26(0-33)\end{array}$ & $\begin{array}{r}17(0-78) \\
0(0-58)\end{array}$ & $\begin{array}{l}69(54-80) \\
40(12-71)\end{array}$ \\
\hline $\begin{array}{c}\text { Second examination: } \\
\text { FSP\% } 15^{\circ} \mathrm{C} \\
100^{\circ} \mathrm{C}\end{array}$ & $\begin{array}{l}6(0-61) \\
6(0-59)\end{array}$ & $\begin{array}{r}18(0-75) \\
0(0-56)\end{array}$ & $\begin{array}{l}13(0-65) \\
0(0-62)\end{array}$ \\
\hline
\end{tabular}


groups was any difference in finger temperature found between the two examinations.

\section{Discussion}

In the present study some patients with VWF reported a subjective improvement after stopping work with vibrating tools, confirming findings in earlier studies. ${ }^{1-5}$ The finding that only one person did not experience any attacks at the reexamination might be due to the relatively short follow up. More than three years of unexposed work was necessary before any subjective improvement was reported. This is in accordance with earlier findings. ${ }^{10}$

It has been suspected that an improvement of VWF symptoms after stopping work with hand held vibrating tools at least partly might be due to diminished cold exposure. ${ }^{45}$ In the present study, however, exposed outdoor workers who changed to unexposed indoor work did not report any improvement until more than three years after change of work. In this group a diminished cold exposure thus preceded any improvement of symptoms with more than three years. Presumably, therefore, the subjective improvement was not primarily related to reduced cold exposure.

Subjective impairment was rare after cessation of exposure, and most patients reporting increased symptoms still worked with vibrating tools or had changed to unexposed work a short time before the reexamination. The symptoms had increased to such an extent that a higher Taylor stage was found on a group basis. Thus even a few extra years of exposed work may result in an impairment. This is in accordance with "dose-response" studies of VWF, in which the disease has been found to progress as the vibration "dose" increased. ${ }^{11}$

Smokers have been shown to have more severe disease than non-smokers, ${ }^{12}$ and VWF is more common in smokers. ${ }^{13}$ The effects of nicotine on the course of the disease could not be evaluated in the present study. Although all patients with VWF are recommended to stop smoking and to avoid exposure to hand arm vibrations, only five patients followed the first recommendation and 37 the second.

The subjective improvement of some patients could not be objectively confirmed at the cold provocation test but since only six patients were completely examined these results must be interpreted with caution. The only "cured" patient actually had closure in his digital arteries after cooling. This is in agreement with observations in another study where an attack of white finger could sometimes be induced by cooling in men who had had no spontaneous attacks for five years. ${ }^{14}$ An increased reactivity to cold was found in the impaired group at the cold provocation test. Thus the cold provocation test seems to provide objective confirmation for the subjective deterioration in thiso subgroup. The cold provocation test must be evaluated with a longer period of follow up than has been? possible here before any definite conclusions can be drawn as to its usefulness in showing an amelioration of symptoms. The test separates, on a group basis, the different Taylor-Pelmear stages, ${ }^{15}$ but within the fol- $\stackrel{\mathbb{\Omega}}{\Omega}$ low up period the subjective improvement of the patients was too slight to be reflected in a lower stage.

This work was supported by a grant from the Swedish $\vec{\omega}$ Work Environment Fund.

\section{References}

1 Stewart AM, Goda DF. Vibration syndrome. Br J Ind Med 1970;27:19-27.

2 Taylor W, Pelmear PL, Pearson JCG. A longitudinal study of Raynaud's phenomenon in chain saw operators. In: Taylor $\mathbf{W},-$ Pelmear PL, eds. Vibration white finger in industry. London: $C$ Academic Press, 1975:15-20.

3 Riddle HFV, Taylor W. Vibration-induced white finger among chain sawers nine years after the introduction of anti-vibrationco measures. In: Brammer AJ, Taylor W, eds. Vibration effects on the hand and arm in industry. New York: Wiley, 1982:169-72.'

4 Pyykkö I, Korhonen OS, Färkkilä MA, Starck JP, Aatola SA. AO longitudinal study of the vibration syndrome in Finnish forestry workers. In: Brammer AJ, Taylor W, eds. Vibration effects on the hand and arm in industry. New York: Wiley, 1982:156-67.

5 Futatsuka M, Ueno T. Vibration exposure and vibration-induced $\stackrel{\overparen{D}}{\Omega}$ white finger due to chain saw operation. J Occup Med 1985;27:257-64.

6 Taylor W, Brammer AJ. Vibration effects on the hand and arm in industry: an introduction and review. In: Brammer AJ, Taylor? $\mathrm{W}$, eds. Vibration effects on the hand and arm in industry. NewO York: Wiley, 1982:1-12.

7 Taylor W, Pelmear PL, eds. Vibration white finger in industry London: Academic Press, 1975:xxi.

8 Nielsen SL. Raynaud phenomena and finger systolic pressuré during cooling. Scand J Clin Lab Invest 1978;38:765-70.

9 Ekenvall L, Lindblad LE. Digital blood pressure after local cool ing as a diagnostic tool in traumatic vasospastic disease. $\mathrm{Br}$ Ind Med 1982;39:388-91.

10 Futatsuka M, Ueno T, Sakurai T. Follow up study of vibrationo induced white finger in chain saw operators. $\mathrm{Br} J$ Ind $\mathrm{Med}$ 1985;42:267-71.

11 Brammer AJ. Relations between vibration exposure and the development of the vibration syndrome. In: Brammer $\mathrm{AJ}_{\mathrm{N}}$ Taylor $\mathrm{W}$, eds. Vibration effects on the hand and arm in indus $\mathrm{Cr}$ try. New York: Wiley, 1982:283-90.

12 Ekenvall L, Lindblad LE. Vibrationsutlösta Raynaudfenomen och nikotinkonsumtion-en preliminär rapport. Opusculaw Medica 1985;30:28-31.

13 Thériault G, De Guire L, Gingras S, Laroche G. Raynaud's phenomenon in forestry workers in Quebec. Can Med Assoc 1982;126:1404-8.

14 Pyykkö I, Sairanen E, Korhonen O, Färkkilä M, Hyvärinen J. A decrease in the prevalence and severity of vibration-inducedo white fingers among lumberjacks in Finland. Scand $J$ Work Environ Health 1978;4:246-54.

15 Ekenvall L, Lindblad LE. Vibration white finger and digital sys tolic pressure during cooling. Br J Ind Med 1986;43:280-3. 